\title{
Kidney Regeneration in Mammals
}

\author{
Hai-Chun Yang Shao-Jun Liu Agnes B. Fogo \\ Department of Pathology, Microbiology and Immunology, Vanderbilt University Medical Center, Nashville, Tenn., USA
}

\section{Key Words}

Regeneration · Mammals · Nephron

\begin{abstract}
Background: Several organs such as the skin and liver have a great capacity for regeneration. However, many approaches only delay the progression of end-stage kidney disease and do not achieve efficient long-term stabilization, let alone regeneration. Summary: In mammals, the kidney has an innate but limited capacity for regeneration which can only modify the nephron structure and function but not increase the nephron number. Several clinical and animal studies have indicated that functional improvements and/or structural regression can occur in chronic kidney disease. Cell reconstitution, matrix remodeling, and tissue reorganization are major mechanisms for kidney regeneration. Current approaches achieve only partial kidney regeneration, but this does not occur in all animals and is not sustained in the long term. Multipronged and early interventions are future choices for the induction of kidney regeneration. Key Messages: Kidney regeneration in mammals is feasible but limited and may be enhanced by multitargeting key mechanisms.
\end{abstract}

(c) 2014 S. Karger AG, Basel

\section{KARGER}

(C) 2014 S. Karger AG, Base

$1660-2129 / 14 / 1262-0050 \$ 39.50 / 0$

E-Mail karger@karger.com

www.karger.com/nee

\section{Introduction}

The principles of strategies for progressive kidney diseases focus on control of the blood pressure, decreasing proteinuria, and immunosuppression. However, in most cases, these approaches only delay the progression of endstage renal disease and do not achieve efficient long-term stabilization, let alone improvement, of renal function. In mammals, several organs such as the skin and liver have a great capacity for regeneration. The kidney also has an innate capacity for regeneration, especially after tubular necrosis. However, this capacity is limited, particularly for glomerular remodeling after injury, perhaps due to its complex cells and architecture. We will discuss potential mechanisms of kidney regeneration and whether this goal can be achieved in mammals.

\section{What Is Kidney Regeneration?}

In biology, regeneration is the process of renewal, restoration, and growth that results in cells, tissues, and organs being restored to their natural morphology and function. Regeneration can be either complete, when the new tissue is the same as the lost tissue, or incomplete, as 
for instance when necrotic tissue becomes fibrotic. Regression or remission of disease is on the opposite end of the spectrum of disease outcomes in relation to progression, the characteristic phenomenon of chronic kidney disease. Regeneration is the process of tissue repair, including regression of the disease, structure remodeling, and new organogenesis.

Attenuation of the regenerative capacity during evolution is a general phenomenon, presumably due to increased organism complexity during evolutionary adaptations [1]. In fish and other lower branches of the animal kingdom, nephron progenitors are retained throughout life, and these progenitors can replace damaged or lost nephrons and thereby restore the adult nephron (socalled nephron neogenesis). In contrast, in mammals nephron progenitors are lost at the end of kidney organogenesis once the adult number of nephrons has been reached. During postnatal growth, increases in renal demand are met by concomitant increases in nephron size (hyperplasia and hypertrophy) and filtration [2]. Thus, kidney regeneration in mammals can only modify the nephron structure and function but not increase the nephron number.

Different parts of the nephron have different capacities for regeneration. Tubules, especially the proximal tubule, can regenerate after an acute injury. In contrast, the complex architecture of the glomerulus makes its regeneration the most difficult challenge for organ regenerative therapy. In this review, we will focus on the regeneration of injured glomeruli.

\section{Evidence of Kidney Regeneration}

Several clinical observations support the potential of kidney regeneration. The precedent that some early-tomoderate glomerular lesions can regress comes from biopsy analysis of diabetic patients who received pancreas transplants $[3,4]$. In the REIN core study of nondiabetic nephrotic patients, ramipril treatment for 2 years resulted in amelioration of the glomerular filtration rate (GFR) decline to a yearly loss similar to that which occurs with normal aging. Further, 10 of 78 treated patients in this study showed improvement of the GFR and never reached end-stage renal disease [5]. In another long-term followup study on diabetic nephropathy, 7 of 42 patients on captopril had full remission of proteinuria and stabilized renal function. After an 8-year extended follow-up period, the GFR remained stable in 6 patients who still had less than $1 \mathrm{~g} / 24 \mathrm{~h}$ of proteinuria [6]. These findings show that remission and even regression of the functional parameters of chronic kidney disease can occur in humans. Whether these functional improvements were contributed to in part by any regression of structural injury remains unknown.

Animal studies may help to clarify the significance of findings in humans and support the possibility of structural lesion regression. A recent study showed that replacing leptin reversed the diabetic nephropathy lesions modeled by the leptin-deficient BTBR ob/ob mouse [7]. We and other groups have proven that high-dose ACE inhibitor angiotensin receptor blocker (ARB) or inhibition of aldosterone can reverse proteinuria and glomerulosclerosis in models of chronic puromycin aminonucleoside nephropathy, hypertensive injury, and subtotal nephrectomy and in aging rats [8-12]. The high-dose ACE inhibitor remodeled the glomerular architecture by reducing the sclerosis volume and enlarging the volume of intact capillaries by up to $40 \%$ [13]. Mesangial and endothelial cell proliferation was reversed, but the number of podocytes per glomerulus was not changed by ACE inhibitor treatment [14]. We also found that glomeruli in rats with progressive sclerosis were enlarged but had a reduced number of capillary segments and capillary branch points and a decreased complexity of the glomerular network compared to normal glomeruli. In contrast, in rats with regression of sclerosis induced by ARB, glomerular enlargement was due to an increased number of glomerular capillary segments and capillary branch points and restored complexity of the capillary network [15]. These structural changes support that regeneration of portions of glomeruli with segmental sclerosis may occur.

\section{Mechanisms of Kidney Regeneration}

Kidney regeneration may occur through various steps, including cell reconstitution, matrix remodeling, and tissue reorganization. Cell reconstitution involves the proliferation and transdifferentiation of remnant healthy cells, renal progenitor cells, and/or stem cells. After acute kidney injury, surviving resident tubular epithelial cells dedifferentiate and subsequently reenter the cell cycle and replace the injured necrotic tubular epithelium, which may be driven by cells surrounding the tubular compartment through secreted ligands [16]. In glomeruli, mesangial cells and endothelial cells readily proliferate and can be replenished after injury, but podocytes do not, due to a high expression of the cyclin-dependent kinase 
inhibitor p27kip1 [17]. Recently, reversal of glomerulosclerosis in aged MWF rats was observed after high-dose ACE inhibitor, linked to podocyte proliferation, regenerated from the parietal epithelium [18]. Cells of the renin lineage may also enhance glomerular regeneration by serving as progenitors for glomerular epithelial cells and podocytes [19].

Cellular regeneration alone appears to be ineffective in the face of a chronic insult, when increased matrix accumulation modulates cell migration and function. Matrix accumulation is modulated by proteases and their inhibitors, such as the matrix metalloproteases (MMPs) and tissue inhibitors of MMPs (TIMPs), and by factors that promote matrix synthesis, including transforming growth factor- $\beta 1$ (TGF- $\beta 1)$. In our studies of regression in the remnant kidney model, high-dose angiotensin inhibition did not increase MMP mRNA or activity or reduce TGF- $\beta 1$ mRNA. However, regression by ARB was tightly linked to decreases in plasminogen activator inhibitor 1 (PAI-1) and TIMP-1 [11, 20]. We also observed that thymosin- $\beta 4$ is increased in early glomerulosclerosis and is required for angiotensin II-induced PAI-1 expression in glomerular endothelial cells [21]. Thymosin- $\beta 4$ is degraded via a 2-step process to the antifibrotic tetrapeptide $\mathrm{N}$-acetyl-seryl-aspartyl-lysyl-proline (Ac-SDKP), with the initial step mediated by unknown protease(s) and then by prolyl oligopeptidase. Ac-SDKP is degraded by ACE and thus increased by the ACE inhibitor. The regression induced by the ACE inhibitor may be, at least partially, related to the effects of thymosin- $\beta 4$ and AcSDKP.

Chronic kidney disease is characterized by a progressive loss of glomerular capillaries. The podocyte normally secretes specific growth factors, including vascular endothelial growth factor-A (VEGF-A) and angiopoietin-1, which are key for maintaining normal glomerular endothelial function and fenestration. Glomerular VEGF was decreased in the remnant kidney model and, conversely, treatment with VEGF ameliorated the development of glomerulosclerosis and tubulointerstitial fibrosis [22]. In addition to it effects on blood pressure, extracellular matrix, and other growth factors, ARB also promotes direct beneficial effects on podocytes and, in turn, glomerular endothelial cell growth [23]. Elegant studies in a conditional transgenic mouse model demonstrated that a sequential reduction in podocyte VEGF-A levels led to a loss of endothelial fenestrations or failure of fenestrations to form [24]. Our ongoing study supports that overexpression of VEGF in podocytes after glomerular injury stimulates tip cell formation and may accelerate an- giogenesis. Hence, it is proposed that revascularization might be a key process to restore kidney function and regenerate the glomerulus.

\section{Current Approaches and Future Directions}

Although the regression of glomerulosclerosis was achieved in animal studies via angiotensin inhibition, it did not occur in all animals and was not sustained in the long term. We have previously shown that ARB induces the regression of existing glomerulosclerosis in about two thirds of rats during a relatively short period after $5 / 6$ nephrectomy (week 8 to week 12). However, long-term follow-up (from week 8 to week 30) showed only a survival benefit of ARB but no regression of glomerulosclerosis. Further, the glomerular structure was not completely returned to normal by using the ACE inhibitor or ARB, suggesting that additional injury mechanisms such as reactive oxygen species and abnormal cell growth promoting sclerosis were still active. We and others have found that the combination of an aldosterone synthesis inhibitor and ARB, or the combination of PPAR- $\gamma$ agonists and $A R B$, induces more regression of glomerulosclerosis in the $5 / 6$ nephrectomy model. These additional effects were related to less inflammation and more podocyte protection [25]. Combination therapy with an ACEI, ARB, and statin achieved even better results in sclerosis than monotherapy with any one of these classes of drug [26]. Thus, a multipharmacological strategy involving novel anti-inflammatory and antifibrotic molecules should be considered in order to potentiate kidney regeneration.

Regeneration does not uniformly occur even with multimodal therapeutic interventions. This may be dependent not only on the disease model but also on the disease stage. Our long-term study in 5/6 nephrectomy rats showed that earlier stages of sclerosis responded more to ARB than later stages. Our mathematical modeling indicated that individual glomerular tufts with sclerosis occupying $>50 \%$ of the capillaries are doomed to progression. Conversely, glomeruli with $<50 \%$ sclerosis of the tuft are capable of growing new capillary loops. Elegant morphometric studies of CKD in children and rats have demonstrated that both lengthening and branching of glomerular capillaries occurs after injury [27].

Tissue engineering, cell-based therapies and novel agents beyond renin-angiotensin-aldosterone system blockade are among the major fields of investigation in kidney regeneration. The creation of a biocompatible kidney using scaffolds as a skeleton in which to seed renal 
cells or stem cells would be an ideal solution for organ shortages. However, the complexity of the kidney structure is a formidable obstacle. Alternatively, the application of stem cells, direct lineage conversion, and reprogramming of existing cells to kidney progenitor cells may be feasible approaches to slowing the progression of chronic kidney disease or even reversing it.
In summary, kidney regeneration in mammals is feasible but limited. Cell reconstitution, matrix remodeling, and tissue reorganization are major mechanisms for regeneration. Multipronged and early interventions are future choices for the induction of kidney regeneration.

\section{References}

1 Romagnani P: From Proteus to Prometheus: learning from fish to modulate regeneration. J Am Soc Nephrol 2010;21:726-728.

$\checkmark 2$ Davidson AJ: Uncharted waters: nephrogenesis and renal regeneration in fish and mammals. Pediatr Nephrol 2011;26:1435-1443.

-3 Fioretto P, Steffes MW, Sutherland DE, Goetz FC, Mauer M: Reversal of lesions of diabetic nephropathy after pancreas transplantation. N Engl J Med 1998;339:69-75.

4 Fioretto P, Sutherland DE, Najafian B, Mauer $\mathrm{M}$ : Remodeling of renal interstitial and tubular lesions in pancreas transplant recipients. Kidney Int 2006;69:907-912.

$\checkmark 5$ Ruggenenti P, Perna A, Benini R, Bertani T, Zoccali C, Maggiore Q, Salvadori M, Remuzzi G: In chronic nephropathies prolonged ACE inhibition can induce remission: dynamics of time-dependent changes in GFR. Investigators of the GISEN Group. Gruppo Italiano Studi Epidemiologici in Nefrologia. J Am Soc Nephrol 1999;10:997-1006.

6 Wilmer WA, Hebert LA, Lewis EJ, Rohde RD, Whittier F, Cattran D, Levey AS, Lewis JB, Spitalewitz S, Blumenthal S, Bain RP: Remission of nephrotic syndrome in type 1 diabetes: long-term follow-up of patients in the captopril study. Am J Kidney Dis 1999;34:308-314.

$\checkmark 7$ Pichaiwong W, Hudkins KL, Wietecha T, Nguyen TQ, Tachaudomdach C, Li W, Askari B, Kobayashi T, O’Brien KD, Pippin JW, Shankland SJ, Alpers CE: Reversibility of structural and functional damage in a model of advanced diabetic nephropathy. J Am Soc Nephrol 2013;24:1088-1102.

8 Marinides GN, Groggel GC, Cohen AH, Border WA: Enalapril and low protein reverse chronic puromycin aminonucleoside nephropathy. Kidney Int 1990;37:749-757.

>9 Ma LJ, Nakamura S, Whitsitt JS, Marcantoni C, Davidson JM, Fogo AB: Regression of sclerosis in aging by an angiotensin inhibitioninduced decrease in PAI-1. Kidney Int 2000 58:2425-2436.

-10 Adamczak M, Gross ML, Krtil J, Koch A, Tyralla K, Amann K, Ritz E: Reversal of glomerulosclerosis after high-dose enalapril treatment in subtotally nephrectomized rats. J Am Soc Nephrol 2003;14:2833-2842.
11 Aldigier JC, Kanjanbuch T, Ma LJ, Brown NJ, Fogo AB: Regression of existing glomerulosclerosis by inhibition of aldosterone. J Am Soc Nephrol 2005;16:3306-3314.

12 Boffa JJ, Lu Y, Placier S, Stefanski A, Dussaule JC, Chatziantoniou C: Regression of renal vascular and glomerular fibrosis: role of angiotensin II receptor antagonism and matrix metalloproteinases. J Am Soc Nephrol 2003; 14:1132-1144.

13 Remuzzi A, Gagliardini E, Sangalli F, Bonomelli M, Piccinelli M, Benigni A, Remuzzi G: ACE inhibition reduces glomerulosclerosis and regenerates glomerular tissue in a model of progressive renal disease. Kidney Int 2006; 69:1124-1130.

14 Adamczak M, Gross ML, Amann K, Ritz E: Reversal of glomerular lesions involves coordinated restructuring of glomerular microvasculature. J Am Soc Nephrol 2004;15:30633072 .

15 Scruggs BS, Zuo Y, Donnert E, Ma L, Bertram JF, Fogo AB: Increased capillary branching contributes to angiotensin type 1 receptor blocker (ARB)-induced regression of sclerosis. Am J Pathol 2011;178:1891-1898.

16 Bonventre JV, Yang L: Cellular pathophysiology of ischemic acute kidney injury. J Clin Invest 2011;121:4210-4221.

17 Combs HL, Shankland SJ, Setzer SV, Hudkins KL, Alpers CE: Expression of the cyclin kinase inhibitor, p27kip1, in developing and mature human kidney. Kidney Int 1998;53:892-896.

18 Macconi D, Sangalli F, Bonomelli M, Conti S, Condorelli L, Gagliardini E, Remuzzi G, Remuzzi A: Podocyte repopulation contributes to regression of glomerular injury induced by ace inhibition. Am J Pathol 2009;174:797807.

19 Pippin JW, Sparks MA, Glenn ST, Buitrago S, Coffman TM, Duffield JS, Gross KW, Shankland SJ: Cells of renin lineage are progenitors of podocytes and parietal epithelial cells in experimental glomerular disease. Am J Pathol 2013;183:542-557.
20 Ma LJ, Nakamura S, Aldigier JC, Rossini M, Yang H, Liang X, Nakamura I, Marcantoni C, Fogo AB: Regression of glomerulosclerosis with high-dose angiotensin inhibition is linked to decreased plasminogen activator inhibitor-1. J Am Soc Nephrol 2005;16:966976.

21 Xu BJ, Shyr Y, Liang X, Ma LJ, Donnert EM, Roberts JD, Zhang X, Kon V, Brown NJ, Caprioli RM, Fogo AB: Proteomic patterns and prediction of glomerulosclerosis and its mechanisms. J Am Soc Nephrol 2005;16: 2967-2975.

-22 Kang DH, Hughes J, Mazzali M, Schreiner GF, Johnson RJ: Impaired angiogenesis in the remnant kidney model. 2. Vascular endothelial growth factor administration reduces renal fibrosis and stabilizes renal function. J Am Soc Nephrol 2001;12:1448-1457.

23 Liang XB, Ma LJ, Naito T, Wang Y, Madaio M, Zent R, Pozzi A, Fogo AB: Angiotensin type 1 receptor blocker restores podocyte potential to promote glomerular endothelial cell growth. J Am Soc Nephrol 2006;17:18861895.

-24 Eremina V, Sood M, Haigh J, Nagy A, Lajoie G, Ferrara N, Gerber HP, Kikkawa Y, Miner JH, Quaggin SE: Glomerular-specific alterations of VEGF-A expression lead to distinct congenital and acquired renal diseases. J Clin Invest 2003;111:707-716.

25 Nemeth Z, Kokeny G, Godo M, Mozes M, Rosivall L, Gross ML, Ritz E, Hamar P: Increased renoprotection with ace inhibitor plus aldosterone antagonist as compared to monotherapies - the effect on podocytes. Nephrol Dial Transplant 2009;24:3640-3651.

26 Zoja C, Corna D, Camozzi D, Cattaneo D, Rottoli D, Batani C, Zanchi C, Abbate M, Remuzzi G: How to fully protect the kidney in a severe model of progressive nephropathy: a multidrug approach. J Am Soc Nephrol 2002; 13:2898-2908.

27 Fogo AB: Progression and potential regression of glomerulosclerosis. Kidney Int 2001; 59:804-819. 